\title{
Brace treatment can serve as a time-buying tactic for patients with congenital scoliosis
}

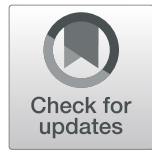

Yuwen Wang ${ }^{1 \dagger}$, Zongxian Feng ${ }^{2 \dagger}$, Zhichong Wu' ${ }^{1}$, Yong Qiu', Zezhang Zhu ${ }^{1}$ and Leilei Xu ${ }^{1 *}$ (D)

\begin{abstract}
Background: Infantile patients with congenital scoliosis (CS) can be confronted with increasing risk of mortality and morbidity. To date, the effectiveness of conservative treatment in CS has not been sufficiently investigated. We aimed to evaluate the bracing outcome in patients with CS and to investigate whether wearing brace can effectively delay the surgical procedures.

Methods: A total of 39 braced CS patients including 25 boys and 14 girls were reviewed for the eligibility to be included in this study. Radiographic parameters including curve magnitude and T1 to T12 height were evaluated for each patient at the initiation of the treatment and at the final follow-up (FU), respectively. Duration of the follow-up and requirement of surgical interventions were also recorded. The student $t$ test was used to compare the radiographic parameters between the initial visit and the last FU.
\end{abstract}

Results: The mean initial age at bracing was $4.1 \pm 2.3$ years, and $7.5 \pm 1.8$ brace modifications were performed during a mean FU period of $42.1 \pm 26.5$ months. The mean curve magnitude before bracing was $44.1 \pm 12.2^{\circ}$, which was corrected to $41.3 \pm 13.5^{\circ}$ at the final visit $(p=0.33)$. T1-T12 height increased from $13.4 \pm 2.5$ to $17.1 \pm 2.8 \mathrm{~cm}$ during the treatment $(P<0.001)$. Nine patients underwent surgical intervention due to the curve progression more than $5^{\circ}$, with the time of surgery delayed for $32.1 \pm 18.2$ months.

Conclusions: Brace treatment is an effective time-buying modality for CS patients, which may help maintain the body growth and delay the surgical intervention.

Keywords: Congenital scoliosis, Brace treatment, Effectiveness

\section{Background}

Congenital scoliosis (CS) is a rare type of spinal deformity secondary to congenital vertebral malformation (CVM) with an incidence of $0.1 \%$ approximately [1]. Usually, the severity of the congenital scoliosis is dependent on CVM type, location and number, as well as the patients' age [2-4]. Previous studies have demonstrated that most congenital scoliosis may be progressive [5-7]. McMaster et al. [8] concluded that curve progression depends on the type of CVM and the spinal region involved. Hemivertebra and thoracic curves are associated with the poorest prognosis. Without appropriate treatment, infantile patients with CS can be confronted with increasing risk of mortality and morbidity concomitant with cardiopulmonary dysfunction [9].

\footnotetext{
* Correspondence: peterxu_drumtower@163.com

†Yuwen Wang and Zongxian Feng contributed equally to this work.

${ }^{1}$ The Affiliated Drum Tower Hospital of Nanjing University Medical School,

Zhongshan Road 321, Nanjing 210008, China

Full list of author information is available at the end of the article
}

Progressive CS in the immature spine poses unique management challenges for the surgeons with limited intervention modalities available. Several treatment options exist to correct deformity or prevent progression, including casting, in situ fusion, growing rods, and vertical expandable prosthetic titanium rib [10-13]. In earlier literatures concerning treatment of patients with CS, the choice of age at surgery was still in debate [14-16]. Some authors proposed to perform surgery such as epiphysiodesis or CVM resection at a very early age, while others argued that fusion surgery at early stage of the patients was not an effective means of treatment due to the premature growth arrest of the spine and thoracic cage $[15,16]$. Moreover, multiple surgical exposures and an increased risk of associated complications such as infections and implant failure have confined the effectiveness of early-stage surgery for CS. Gradually, it was well accepted that desirable correction treatment should allow for continued

(c) The Author(s). 2019 Open Access This article is distributed under the terms of the Creative Commons Attribution 4.0 International License (http://creativecommons.org/licenses/by/4.0/), which permits unrestricted use, distribution, and 
spinal growth and maturation of the lung tissues which commonly occurs at the age of 8 years [15]. Thus, before this age, delaying tactics alternative to fusion should be actively applied to the patients.

Cast correction represents another alternative for scoliosis, which was widely used before spinal instrumentation [17-19]. Recent studies showed that serial casting may help delay the growing rod surgery for early-onset scoliosis (EOS), which could decrease the incidence of complications related to surgical procedures [19-21]. Conservative techniques are conventionally considered inappropriate for patients with CS due to the progressive spinal deformity. Nevertheless, taking advantage of delay of the initial surgery, recently serial casting has been applied to the treatment of CS [10, 11]. Demirkiran et al. [11] reviewed a total of 11 CS patients treated with serial cast application and reported that it is a safe and effective time-buying strategy to delay the surgical interventions in congenital deformities. Cao et al. [10] also reported that casting is an efficient treatment option to delay the surgery for CS patients. As the aforementioned reports included a small cohort of patients, the role of serial casting in CS has not been sufficiently investigated. As a conservative modality similar with serial casting, brace treatment has been applied to CS patients of our clinic center for a few years. The objectives of this study were to evaluate the bracing outcome in patients with CS, and to investigate whether wearing brace can effectively delay the surgical procedures.

\section{Methods}

\section{Subjects}

Under the approval of the local Institutional Review Board, we reviewed all the patients undergoing brace treatment for EOS between May 2005 and June 2015 at our scoliosis center. The inclusion criteria were as follows: (1) diagnosed as congenital scoliosis or infantile idiopathic scoliosis (IIS), (2) with an initial Cobb angle of less than $50^{\circ}$, (3) aged younger than 8 years, (4) receiving no other treatment prior to bracing, and (5) with the bracing period longer than 12 months. The exclusion criteria were as follows: (1) with short and sharp angular congenital deformities secondary to hemivertebra and (2) with the treatment discontinued due to complications such as neurological impairment and skin irritation. A cohort of 39 CS patients and 24 IIS patients were finally included in the study.

\section{Bracing strategy}

For CS patients, apical region of the kyphosis was well padded to prevent skin ulcers. Each patient was initially instructed to wear the brace for $22 \mathrm{~h}$. Routine follow-up visit was carried out at an interval of 3 month, and the brace was modified according to the growth status of the patients. The brace treatment was discontinued in case of curve progression beyond $50^{\circ}$. Standard standing posteroanterior and lateral out-of-cast radiographs were taken at each visit for radiographic evaluation.

\section{Data collection}

Baseline demographics including initial age, Risser sign, curve pattern, duration of treatment, number of brace modified, requirement of surgery, and bracing-related complications were collected. Radiographic measurements including major curve magnitude, T1 to T12 height, coronal balance, and sagittal balance were evaluated for each patient at the initiation of the treatment and at the final visit, respectively. The coronal balance was evaluated by the horizontal distance between $\mathrm{C} 7$ plumb line (C7PL) and center sacral vertical line (CSVL). The sagittal balance was evaluated by sagittal vertical axis (SVA).

\section{Statistical analysis}

The software Statistical Package for the Social Sciences (SPSS, version 19.0) was used for statistical analyses. Continuous variables were summarized as the mean value $\pm \mathrm{SD}$. The correction rate was calculated as follows: (pre-brace angle - final-visit angle)/pre-brace angle $\times 100 \%$. The Student $t$ test was used for comparisons of continuous variables. The Chi-square test was used for comparisons of categorical variables. Statistical significance was set at a $p$ value of 0.05 .

\section{Results}

The baseline characteristics of the subjects were summarized in the Table 1 . The two groups were matched in terms of initial age, gender, and initial curve magnitude. For the CS group, there were 14 female and 25 male patients. All patients had long congenital curves with formation $(n=27)$ or segmentation anomalies $(n=12)$. Thirty-three patients had main thoracic curve and six patients had lumbar or thoracolumbar curve. As for skeletal maturity, all the patients had an initial Risser sign of stage 0 . The mean initial age was $4.1 \pm 2.3$ years (range, 1.5 to 7 years). The average number of brace modifications was $7.5 \pm 1.8$ (range, 2 to 12 times). The mean period of brace treatment was $42.1 \pm 26.5$ months (14118 months).

The radiographic data of the subjects were summarized in the Table 2. For CS patients, the mean curve magnitude

Table 1 The baseline characteristics of the CS patients and the IIS patients

\begin{tabular}{llll}
\hline & CS $(n=39)$ & IS $(n=24)$ & $P$ \\
\hline Age (years) & $4.1 \pm 2.3$ & $4.3 \pm 2.1$ & 0.73 \\
Ratio of male to female & $25: 14$ & $15: 9$ & 0.88 \\
Duration of brace treatment (months) & $42.1 \pm 26.5$ & $48.4 \pm 13.7$ & 0.19 \\
Number of brace modifications & $7.5 \pm 1.8$ & $6.8 \pm 1.5$ & 0.08 \\
Initial curve magnitude $\left(^{\circ}\right)$ & $44.1 \pm 12.2$ & $38.5 \pm 13.5$ & 0.10 \\
\hline
\end{tabular}


Table 2 Comparison of bracing outcome in the two groups

\begin{tabular}{llll}
\hline & CS $(n=39)$ & IIS $(n=24)$ & $P$ \\
\hline Final curve magnitude $\left(^{\circ}\right)$ & $41.3 \pm 13.5$ & $29.8 \pm 10.4$ & $<0.001$ \\
Curve correction rate & $14.8 \% \pm 13.5 \%$ & $28.2 \% \pm 11.6 \%$ & $<0.001$ \\
$\begin{array}{l}\text { Incidence of curve } \\
\text { progression }\end{array}$ & $23.1 \%$ & $16.7 \%$ & 0.54 \\
$\begin{array}{l}\text { Growth rate of T1-T12 } \\
\text { (cm/year) }\end{array}$ & $1.02 \pm 0.21$ & $1.07 \pm 0.18$ & 0.33 \\
\hline
\end{tabular}

before bracing was $44.1 \pm 12.2^{\circ}$, which was corrected to $41.3 \pm 13.5^{\circ}$ at the final visit $(p=0.33)$. Twenty $(51.3 \%)$ patients were found to have curve correction of more than $5^{\circ}$ (Fig. 1). Nine (23.1\%) patients were found to have curve progression of more than $5^{\circ}$ (Fig. 2). Kyphotic deformity was observed in eight patients. The local kyphosis angle was reduced from $58.4 \pm 11.3^{\circ}$ to $52.3 \pm 11.9^{\circ}(p=0.02)$. The mean T1 to T12 height before the brace treatment was $13.4 \pm 2.5 \mathrm{~cm}$. At the final visit, it significantly increased to a mean value of $17.1 \pm 2.8 \mathrm{~cm}(p<0.001)$, with an average growth rate of $1.02 \pm 0.21 \mathrm{~cm} /$ year. Before bracing, the coronal and sagittal balance were averaged $13.4 \pm 9.1 \mathrm{~mm}$ and $23.6 \pm 13.9 \mathrm{~mm}$, which were reduced to $12.1 \pm 6.2 \mathrm{~mm}$ and $18.5 \pm 13.4 \mathrm{~mm}$ at the latest followup ( $p=0.46$ for C7PL-CSVL; $p=0.10$ for SVA), respectively. As shown in Table 2, patients with IIS were found to have significantly better correction rate than patients with CS $(28.2 \% \pm 11.6 \%$ vs. $14.8 \% \pm 13.5 \%, p<0.001)$. The incidence of curve progression was higher in the CS group than in the IIS group $(23.1 \%$ vs. $16.7 \%, p=0.54)$. The growth rate of thoracic spine was comparable between the two groups $(1.02 \pm 0.21$ vs. $1.07 \pm 0.18, p=0.33)$.

At the time of the last visit, growing rod surgery was performed for nine patients, who had worn the brace for an average of $32.1 \pm 18.2$ months (range, 14-59 months). The mean age at surgery was $5.6 \pm 2.2$ years (range, 4-10 years). As shown in Table 3 , there was no significant difference between patients with curve progression and those without curve progression in terms of initial age, curve magnitude, or curve pattern. As for the complications, five patients in the CS group reported skin ulcers due to the kyphotic deformity, which were subsequently alleviated after the modification of the brace. There was no other type of complication for both groups.

\section{Discussion}

Treatment of CS in infantile and juvenile patients remains a great challenge in clinical practice. Growth-friendly techniques such as growing rods and vertical expandable prosthetic titanium rib (VEPTR) gained popularity in management of all types of EOS, including congenital scoliosis [12, 13, 15]. However, it is still under debate whether surgical intervention can alter the natural history of CS with a favorable outcome. Both above-mentioned methods require frequently recurrent surgical interventions and have a high incidence of complications. On the other side, serial casting or bracing as a standalone treatment method for scoliosis in young children has been widely used. Most current studies supported their role as a definitive treatment modality in the management of mild curves for patients with $\operatorname{EOS}[15,18,21]$. As for the CS, however, few data are available since most congenital scoliotic curves are believed to be resistant to serial casting and bracing.

To investigate whether bracing can be effectively used for the treatment of CS, we reviewed the bracing outcome in a cohort of 39 CS patients. In this study, significant correction of the major curve was observed at the latest

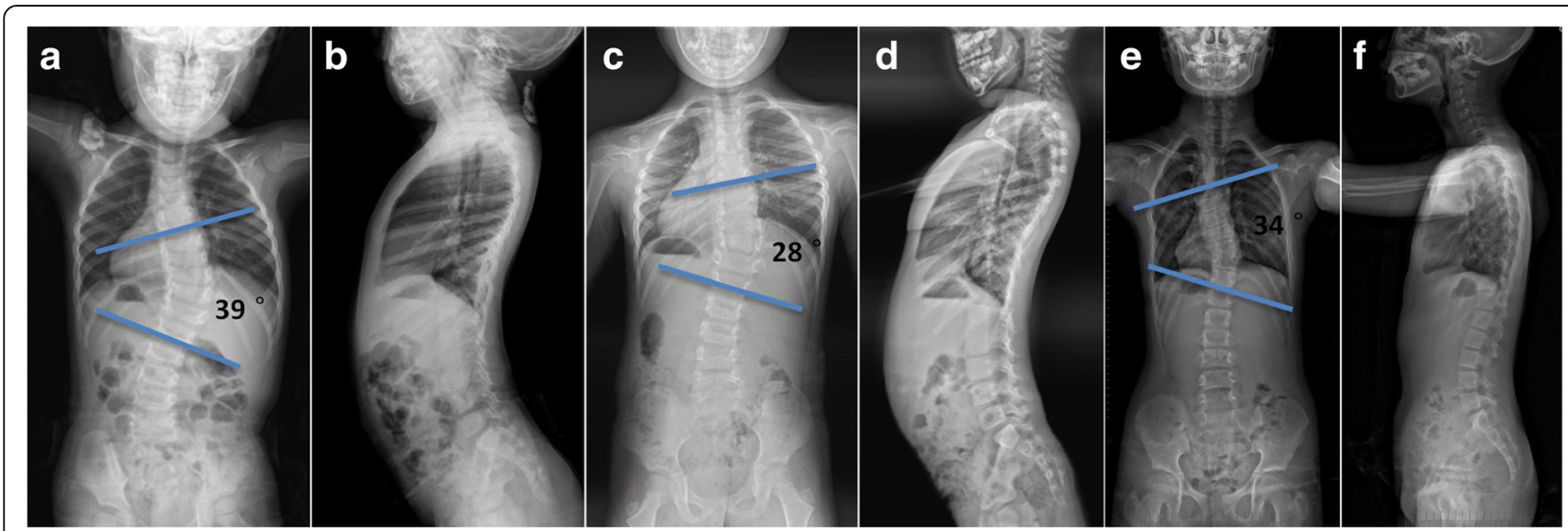

Fig. 1 Radiographs of a patient with favorable outcome of bracing. a, b A 2-year-old female CS patient. Before brace treatment, the curve magnitude was $39^{\circ}$. The T1-T12 height was $129.9 \mathrm{~mm}$. The coronal balance and the sagittal balance were $12.8 \mathrm{~mm}$ and $28.34 \mathrm{~mm}$, respectively. $\mathbf{c}$ d 28 months after brace treatment, the curve magnitude was corrected to $28^{\circ}$. The T1-T12 height increased to 157.8 mm. The coronal balance and the sagittal balance were $12.5 \mathrm{~mm}$ and $3.8 \mathrm{~mm}$, respectively. e, f 54 months after brace treatment, the curve magnitude was $34^{\circ}$. The T1-T12 height increased to $175.6 \mathrm{~mm}$. The coronal balance and the sagittal balance were $9.8 \mathrm{~mm}$ and $11.9 \mathrm{~mm}$, respectively 


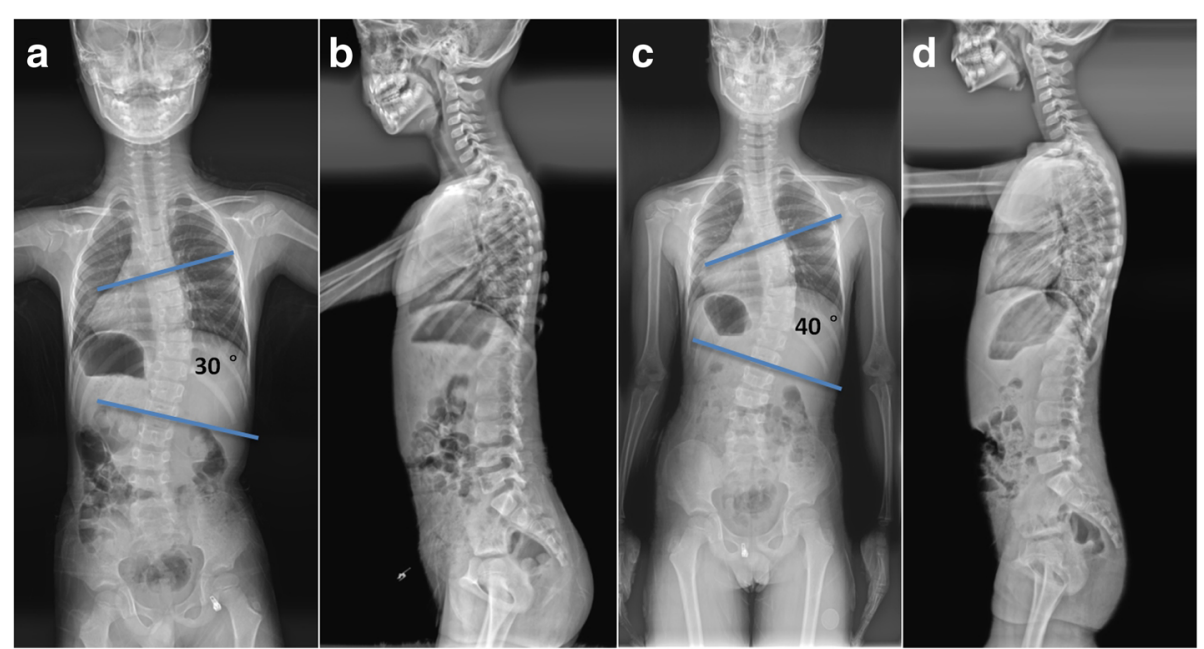

Fig. 2 Radiographs of a patient with curve progression after bracing. a, b A 6-year-old male CS patient. Before brace treatment, the curve magnitude was $30^{\circ}$. The T1-T12 height was $176.5 \mathrm{~mm}$. The coronal balance and the sagittal balance were $12.7 \mathrm{~mm}$ and $11.4 \mathrm{~mm}$, respectively. $\mathbf{c}$, d 19 months after brace treatment, the curve magnitude progressed to $40^{\circ}$. The T1-T12 height increased to $193.4 \mathrm{~mm}$. The coronal balance and the sagittal balance were $10.1 \mathrm{~mm}$ and $15.2 \mathrm{~mm}$, respectively

visit, with a mean correction rate of $14.8 \%$. Over half of the patients (51.3\%) were observed to have an improvement of the curve that was more than $5^{\circ}$. Comparably, Demirkiran et al. [11] have reported a correction rate of $22 \%$ in 11 CS patients receiving casting treatment. Ten out of the 11 patients had the curve corrected by more than $5^{\circ}$. In the study of Cao et al. [10], the mean correction rate was $20.5 \%$ for the CS group. Taken together, the curve progression in CS patients can be controlled through bracing, and the therapeutic effects were maintained well. Moreover, we compared variables between patients with curve progression and those without curve progression, while no significant difference in terms of these variables was observed. It was probably due to the small sample size that leads to weak statistical power to detect influential factors. In future study, recruitment of more CS patients who received brace treatment is warranted to investigate factors associated with curve progression.

In previous studies, serial casting has been proven an effective treatment to delay the first surgery for EOS

Table 3 Assessment of variables related to curve progression in CS patients

\begin{tabular}{llll}
\hline Variables & $\begin{array}{l}\text { Patients with } \\
\text { curve progression } \\
(n=9)\end{array}$ & $\begin{array}{l}\text { Patients without } \\
\text { curve progression } \\
(n=30)\end{array}$ & $P$ \\
\hline Initial age & $3.6 \pm 1.6$ & $4.3 \pm 2.1$ & 0.37 \\
$\begin{array}{l}\text { Initial curve magnitude } \\
\text { Curve pattern }\end{array}$ & $47.1 \pm 11.5$ & $43.2 \pm 12.6$ & 0.41 \\
$\begin{array}{l}\text { Thoracic curve } \\
\text { Thoracolumbar/lumbar } \\
\text { curve }\end{array}$ & 8 & 25 & 0.63 \\
\hline
\end{tabular}

patients [18, 21]. Fletcher et al. [21] reported 39 months of delay in surgery for 17 EOS patients, and $72.4 \%$ of them were saved from growing rod surgery. Likewise, Demirkiran et al. [11] reported an average of 26.3 months of delayed surgery in $11 \mathrm{CS}$ patients receiving serial casting. Cao et al. [10] reported that casting treatment delayed the time of first surgery by an average of 15 months for two CS patients. To be noted, these recent reports on CS included a small number of patients with congenital deformities. In this study, nine of the 39 CS patients finally underwent correction surgery after a mean bracing period of 32.1 months. For the other 30 patients, the surgery had been successfully avoided for a mean period of 45.9 months. Apparently, bracing had effectively delayed the time of first surgery for CS patients, although most of them may eventually need surgical interventions.

An important goal of recurrent surgery in children with CS is to maintain the spinal growth and the development of pulmonary function. Under the traction force in casting correction, serial casting correction would help spinal growth according to Hueter-Volkmann law. To investigate how much of this goal could be achieved through brace treatment, we measured spinal height from the T1 to T12 for each patient. Remarkable spinal growth was observed with an average growth rate of $1.02 \mathrm{~cm} /$ year. This finding is similar to a mean thoracic growth rate of $0.72 \mathrm{~cm} /$ year reported by $\mathrm{Cao}$ et al. and $0.81 \mathrm{~cm} /$ year reported by Demirkiran et al. $[10,11]$. It is noteworthy that the spinal grow rate of braced CS patients was lower than the normal range of age-matched children $(1.5 \mathrm{~cm} /$ year $)$ [22]. However, considering the congenital deformities of the patients, we believed that bracing could effectively preserve the growth potential of the spine. 
In this study, a comparison between the CS group and the IIS group showed that brace treatment could benefit both groups of patients, while the therapeutic outcome of CS patients was less favorable than that of the IIS patients. Compared with IIS patients, CS patients have a relative rigid spine, which is more difficult to be corrected by the traction and derotational force of brace treatment. Obviously, bracing can only serve as a delaying tactic but not a definitive treatment method for young patients with CS.

One limitation of the present study needs to be addressed. As an inherent drawback of retrospective study, the small sample size and short follow-up duration may compromise the power of statistical analysis. A multi-center prospective study with larger sample size and long-term follow-up is warranted for further assessment of the therapeutic effect of bracing.

\section{Conclusions}

The primary purpose of conservative treatment in CS patient is to delay the surgical interventions and decrease the number of recurrent surgical procedures. We confirmed that bracing is a safe and effective time-buying strategy to delay the time of surgical interventions for congenital scoliosis. The curve progression can be well controlled through bracing, and the growth potential of the spine can be effectively preserved.

\section{Abbreviations \\ C7PL: C7 plumb line; CS: Congenital scoliosis; CSVL: Center sacral vertical line; CVM: Congenital vertebral malformation; EOS: Early-onset scoliosis; IIS: Infantile idiopathic scoliosis; SPSS: Software Statistical Package for the Social Sciences; SVA: Sagittal vertical axis; VEPTR: Vertical expandable prosthetic titanium rib}

\section{Acknowledgements}

We gratefully acknowledge the support of all doctors in our department.

\section{Funding}

This work was supported by the National Natural Science Foundation of China (Grant No. 81501849).

\section{Availability of data and materials}

Not applicable.

\section{Authors' contributions}

IW and ZF performed the study. ZW participated in the experiment and data collection/statistical analysis/interpretation for the study. YQ and ZZ conceived of the study and participated in its design. LX was responsible for coordination, data collection/interpretation, and proofreading of the final manuscript. All authors read and approved the final manuscript.

\section{Ethics approval and consent to participate}

Approved by the Institutional Review Board (IRB)/Independent Ethics Committee (IEC) of Nanjing Drum Tower Hospital (The Affiliated Drum Tower Hospital of Nanjing University Medical School) at Zhongshan Road 321, Nanjing 210008, China. All subjects provided informed consent to take part in the study.

\section{Consent for publication}

Not applicable.

\section{Competing interests}

The authors declare that they have no competing interests.

\section{Author details}

${ }^{1}$ The Affiliated Drum Tower Hospital of Nanjing University Medical School, Zhongshan Road 321, Nanjing 210008, China. ${ }^{2}$ Ningbo Medical Center Lihuili Eastern Hospital, No. 57 Xingning Road, Ningbo 315000, China.

Received: 18 November 2018 Accepted: 19 June 2019

Published online: 27 June 2019

\section{References}

1. Erol B, Tracy MR, Dormans JP, Zackai EH, Maisenbacher MK, O'Brien ML, Turnpenny PD, Kusumi K. Congenital scoliosis and vertebral malformations: characterization of segmental defects for genetic analysis. J Pediatr Orthop. 2004;24:674-82.

2. Kaspiris A, Grivas TB, Weiss HR. Congenital scoliosis in monozygotic twins: case report and review of possible factors contributing to its development. Scoliosis. 2008;3:17.

3. Nakajima A, Kawakami N, Imagama S, Tsuji T, Goto M, Ohara T. Threedimensional analysis of formation failure in congenital scoliosis. Spine. 2007:32:562-7.

4. Shahcheraghi GH, Hobbi MH. Patterns and progression in congenital scoliosis. J Pediatr Orthop. 1999;19:766-75.

5. Winter RB. Congenital thoracic scoliosis with unilateral unsegmented bar, convex hemivertebrae, and fused concave ribs with severe progression after posterior fusion at age 2: 40-year follow-up after revision anterior and posterior surgery at age 8. Spine. 2012;37:E507-10.

6. Tanaka T. A study of the progression of congenital scoliosis in non-operated cases. Nihon Seikeigeka Gakkai Zasshi. 1988;62:9-22.

7. Nasca RJ, Stilling FH 3rd, Stell HH. Progression of congenital scoliosis due to hemivertebrae and hemivertebrae with bars. J Bone Joint Surg Am. 1975;57:456-66.

8. McMaster MJ, Ohtsuka K. The natural history of congenital scoliosis. A study of two hundred and fifty-one patients. J Bone Joint Surg Am. 1982;64:1128-47.

9. Marks DS, Qaimkhani SA. The natural history of congenital scoliosis and kyphosis. Spine. 2009;34:1751-5.

10. Cao J, Zhang XJ, Sun N, Sun L, Guo D, Qi XY, Bai YS, Sun BS. The therapeutic characteristics of serial casting on congenital scoliosis: a comparison with non-congenital cases from a single-center experience. J Orthop Surg Res. 2017;12:56.

11. Demirkiran HG, Bekmez S, Celilov R, Ayvaz M, Dede O, Yazici M. Serial derotational casting in congenital scoliosis as a time-buying strategy. J Pediatr Orthop. 2015;35:43-9.

12. Atici Y, Akman YE, Balioglu MB, Erdogan S. A comparison of the effects of two different techniques on shoulder balance in the treatment of congenital scoliosis: vertical expandable prosthetic titanium rib and dual growing rod. J Craniovertebr Junction Spine. 2015;6:190-4

13. Yazici M, Emans J. Fusionless instrumentation systems for congenital scoliosis: expandable spinal rods and vertical expandable prosthetic titanium rib in the management of congenital spine deformities in the growing child. Spine. 2009;34:1800-7.

14. Louis ML, Gennari JM, Loundou AD, Bollini G, Bergoin M, Bernard JC, Biot B, Bonnard C, Clement JL, Garin C, et al. Congenital scoliosis: a frontal plane evaluation of 251 operated patients 14 years old or older at follow-up. Orthop Traumatol Surg Res. 2010;96:741-7.

15. Smith JR, Samdani AF, Pahys J, Ranade A, Asghar J, Cahill P, Betz RR. The role of bracing, casting, and vertical expandable prosthetic titanium rib for the treatment of infantile idiopathic scoliosis: a single-institution experience with 31 consecutive patients. Clinical article. J Neurosurg Spine. 2009;11:3-8.

16. Pratt RK, Webb JK, Burwell RG, Cummings SL. Luque trolley and convex epiphysiodesis in the management of infantile and juvenile idiopathic scoliosis. Spine. 1999;24:1538-47.

17. Canavese F, Botnari A, Dimeglio A, Samba A, Pereira B, Gerst A, Granier M, Rousset M, Dubousset J. Serial elongation, derotation and flexion (EDF) casting under general anesthesia and neuromuscular blocking drugs improve outcome in patients with juvenile scoliosis: preliminary results. Eur Spine J. 2016;25:487-94.

18. Iorio J, Orlando G, Diefenbach C, Gaughan JP, Samdani AF, Pahys JM, Betz RR, Cahill PJ. Serial casting for infantile idiopathic scoliosis: radiographic outcomes and factors associated with response to treatment. J Pediatr Orthop. 2017;37:311-6. 
19. Canavese F, Samba A, Dimeglio A, Mansour M, Rousset M. Serial elongationderotation-flexion casting for children with early-onset scoliosis. World J Orthop. 2015;6:935-43.

20. Abraham R, Sponseller PD. Focused molding using adhesive pads in Mehta casting for early-onset scoliosis. Spine Deform. 2014;2:454-9.

21. Fletcher ND, McClung A, Rathjen KE, Denning JR, Browne R, Johnston CE 3rd. Serial casting as a delay tactic in the treatment of moderate-to-severe early-onset scoliosis. J Pediatr Orthop. 2012;32:664-71.

22. Zhang H, Sucato DJ, Nurenberg P, McClung A. Morphometric Analysis of vertebral growth using magnetic resonance imaging in the normal skeletally immature spine. Spine. 2018;43:133-40.

\section{Publisher's Note}

Springer Nature remains neutral with regard to jurisdictional claims in published maps and institutional affiliations.

Ready to submit your research? Choose BMC and benefit from:

- fast, convenient online submission

- thorough peer review by experienced researchers in your field

- rapid publication on acceptance

- support for research data, including large and complex data types

- gold Open Access which fosters wider collaboration and increased citations

- maximum visibility for your research: over $100 \mathrm{M}$ website views per year

At BMC, research is always in progress.

Learn more biomedcentral.com/submissions 